\title{
A importância da visão clínica do cirurgião-dentista na detecção de lesões pré-malignas: relato de caso clínico
}

The importance of the clinical vision of the dentist in the detection of pre-malignant injuries: case report La importancia de la visión clínica del odontólogo en la detección de lesiones pre-malignas: relato de caso clínico

\section{Thyago Leite CAMPOS DE ARAÚJO ${ }^{1}$ \\ Júlio Leite de ARAÚJO JÚNIOR ${ }^{2}$ \\ Emanuelle de Abreu MOREIRA VIEIRA ${ }^{3}$}

\begin{abstract}
${ }^{I}$ Vice-Coordenador do curso de Odontologia do Centro Universitário Dr Leão Sampao - UNILEÃO 63040000, Juazeiro do Norte-CE, Brasil ${ }^{2}$ Residente em Cirurgia e Traumatologia Buco-Maxilo-Facial pela Universidade Federal da Paraíba-UFPB, 58059900,João Pessoa-PB, Brasil ${ }^{3}$ Graduanda em Odontologia pelo Centro Universitário de João Pessoa - UNIPÊ, Graduanda em Fonoterapia pela Universidade Federal da Paraíba - UFPB 58059900,João Pessoa-PB, Brasil
\end{abstract}

\begin{abstract}
Resumo
Introdução: No território brasileiro, a localização anatômica com maior incidência de lesões cancerígenas é em cabeça e pescoço. Sendo caracterizadas como mais agressivas, as lesões localizadas na boca e orofaringe. Afetando, principalmente a capacidade de deglutir e mastigar, no bem estar emocional, na dor e na comunicação. Estes efeitos decorrem da própria doença ou tipo e agressividade do tratamento, gradualmente mais deformantes quando mais tardio o diagnóstico. Objetivo: O presente estudo tem por objetivo relatar um caso de carcinoma in sito em cavidade bucal e orofaringe bem como apresentar uma breve revisão de literatura sobre neoplasias malignas de boca e orofaringe de maior frequência bem como caracterizá-lo clinicamente e alertar sobre os benefícios do diagnóstico precoce. Relato de caso: Paciente, 64 anos, feminina, melanoderma, apresentando lesão eritroplásica em soalho lingual, bordo lateral de língua com extensão para palato mole. Tabagista há 46 anos apresentando ao exame de macroscopia fragmento de tecido mole de formato e superfícies irregulares, consistência elástica, coloração branco acastanhada, medindo em conjunto 1,2 x1,0x 0,5 cm. O exame histopatológico revelou Carcinoma "in situ". Diante do diagnóstico, a paciente foi encaminhada para o tratamento especializado no hospital de referência na região do Cariri. Conclusão: Conclui-se que o exame clínico minucioso da cavidade oral dos pacientes com fatores de risco 2 e/ou que possuam lesões suspeitas é de fundamental importância para profissionais como o Cirurgião-Dentista e Médico.
\end{abstract}

Descritores: Câncer; Boca; Orofaringe; Odontologia.

\section{Abstract}

Introduction: In the Brazilian territory, the anatomical location with the highest incidence of cancerous lesions is in the head and neck. The lesions located in the mouth and oropharynx are characterized as more aggressive. Affecting, mainly the ability to swallow and chew, emotional well-being, pain and communication. These effects stem from the disease itself or type and aggressiveness of the treatment, gradually more deforming when later diagnosis. Objective: This study aims to report a case of carcinoma in the oral cavity and oropharynx as well as to present a brief review of the literature on malignant neoplasms of the mouth and oropharynx of higher frequency, as well as to characterize it clinically and to warn about the benefits of early diagnosis. Case report: Patient, 64 years old, female, melanoderma, presenting erythroplastic lesion on the lingual floor, tongue lateral border with extension to soft palate. A 46-year-old female smoker has presented macroscopic examination with a soft tissue fragment and irregular surfaces, elastic consistency, brownish-white color, measuring $1.2 \times 1.0 \times 0.5 \mathrm{~cm}$. Histopathological examination revealed Carcinoma "in situ". Before the diagnosis, the patient was referred to the specialized treatment in the reference hospital in the Cariri region. Conclusion: A thorough clinical examination of the oral cavity of patients with risk factors and / or suspicious lesions is of fundamental importance for professionals such as the Dental and Medical Surgeon.

Descriptors: Cancer; Mouth; Oropharynx; Dentistry.

\section{Resumen}

Introducción: En el territorio brasileño, la localización anatómica con mayor incidencia de lesiones cancerígenas es en cabeza y cuello. Si se caracterizan como más agresivas, las lesiones localizadas en la boca y la orofaringe. Afectando, principalmente la capacidad de deglutir y masticar, en el bienestar emocional, el dolor y la comunicación. Estos efectos se derivan de la propia enfermedad o tipo y agresividad del tratamiento, gradualmente más deformantes cuando más tardío el diagnóstico. Objetivo: El presente estudio tiene por objetivo relatar un caso de carcinoma in sito en cavidad bucal y orofaringe así como presentar una breve revisión de literatura sobre neoplasias malignas de boca y orofaringe de mayor frecuencia así como caracterizarlo clínicamente y alertar sobre los beneficios del tratamiento diagnóstico precoz. Relato de caso: Paciente, 64 años, femenina, melanoderma, presentando lesión eritroplásica en suelo lingual, borde lateral de lengua con extensión para paladar blando. Tabaquismo hace 46 años presentando al examen de macroscopia fragmento de tejido blando de formato y superficies irregulares, consistencia elástica, coloración blanca parra, midiendo en conjunto $1,2 \mathrm{x} 1,0 \mathrm{x} 0,5 \mathrm{~cm}$. El examen histopatológico reveló Carcinoma in situ. Ante el diagnóstico, la paciente fue encaminada para el tratamiento especializado en el hospital de referencia en la región del Cariri. Conclusión: Se concluye que el examen clínico minucioso de la cavidad oral de los pacientes con factores de riesgo y / o que tienen lesiones sospechosas es de fundamental importancia para profesionales como el Cirujano Dentista y Médico.

Descriptores: Materiales Dentales; Estética Dental; Odontología.

INTRODUÇÃO

O câncer de cabeça e pescoço representa aproximadamente $5 \%$ de todas as neoplasias e atinge cerca de $1,7 \%$ da população brasileira, correspondendo a um grupo grande e heterogêneo de tumores localizados na pele e lábios, cavidade oral, orofaringe, laringe, hipofaringe, nasofaringe, glândulas salivares, cavidade nasal e seios paranasais, meato acústico externo e ouvido médio ${ }^{1}$.

Compreendido como um grupo de neoplasias malignas heterogêneo, divide-se em subgrupos, dentre os quais destaca-se o câncer bucal como o de maior incidência, possuindo origem na mucosa da boca e na mucosa da faringe ${ }^{2,3}$.

O carcinoma epidermóide é o tipo histológico mais frequente entre as neoplasias malignas da cavidade bucal, sendo responsável por 90 a $95 \%$ do total de casos na região de cabeça e pescoço, seguido por neoplasias originadas das glândulas salivares menores, tumores de origem mesenquimal, sarcomas, neoplasias metastáticas, linfomas e leucemias, além de outras doenças mais raras ${ }^{4}$.

O tratamento destas neoplasias é complexo, 
de caráter multidisciplinar e multimodal, sendo sua complexidade inversamente proporcional ao diagnóstico precoce. As taxas de controle local e de sobrevida aumentaram com tratamentos locoregionais avançados nos últimos 30 anos, porém, não mudaram significativamente mais recentemente ${ }^{5}$.

O presente estudo tem por objetivo relatar um caso de carcinoma in sito em cavidade bucal e orofaringe bem como apresentar uma breve revisão de literatura sobre neoplasias malignas de boca e orofaringe de maior frequência bem como caracterizá-lo clinicamente e alertar sobre os benefícios do diagnóstico precoce ${ }^{5}$.

\section{CASO CLÍNICO}

Paciente com 64 anos de idade, sexo feminino, melanoderma, procurou atendimento do CEO-Aurora para avaliar uma lesão eritroplásica no palato e borda de língua. Relatou que já havia sido consultada por três profissionais, sendo submetida a tratamento no qual não houve nenhuma melhora do seu quadro, relatou ser tabagista há 46 anos e que seu pai faleceu de câncer de boca. Durante a anamnese demonstrou extrema ansiedade. No exame físico loco-regional não mostrou alterações.

O exame clínico revelou a presença de área plana, eritroplásica localizada no assoalho de boca, com cerca de $1,0 \mathrm{~cm}$ de diâmetro estendendo para borda lateral de língua e palato mole (Figuras 1 e 2).

Foi solicitada radiografia panorâmica (Figura 3) para verificar se o tecido ósseo estava preservado. Diante dos achados clínicos e radiográficos foi solicitada biopsia incisional. Ao exame macroscópico observou-se fragmento de tecido mole de formato e superfícies irregulares, consistência elástica, coloração branco acastanhada, medindo em conjunto $1,2 \times 1,0 \times 0,5 \mathrm{~cm}$.

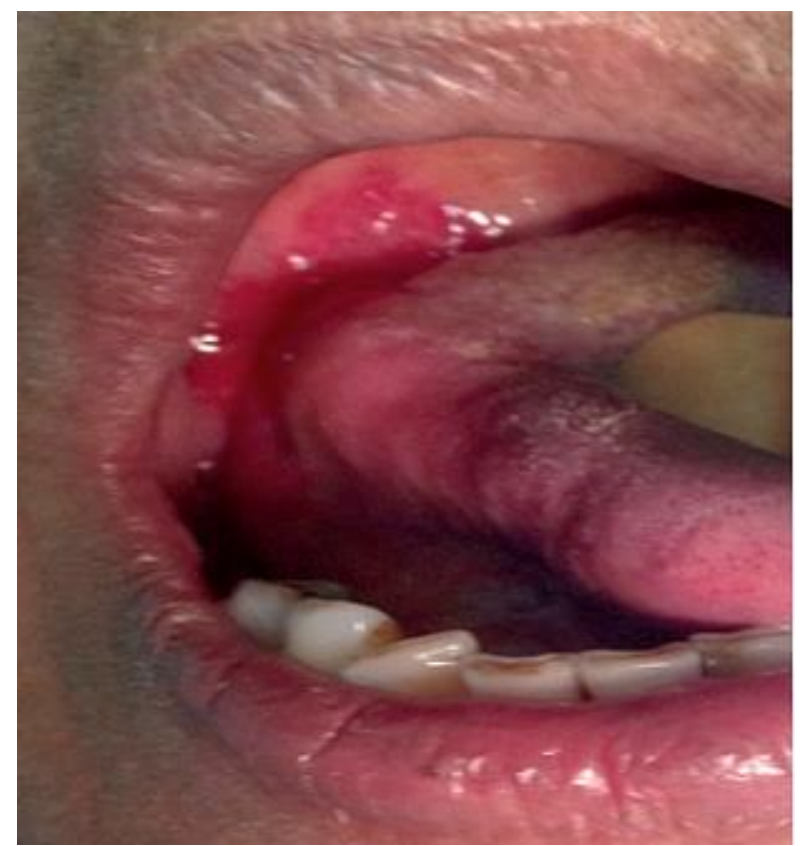

Figura 1: Lesão avermelhada na região posterior e dorso da língua.

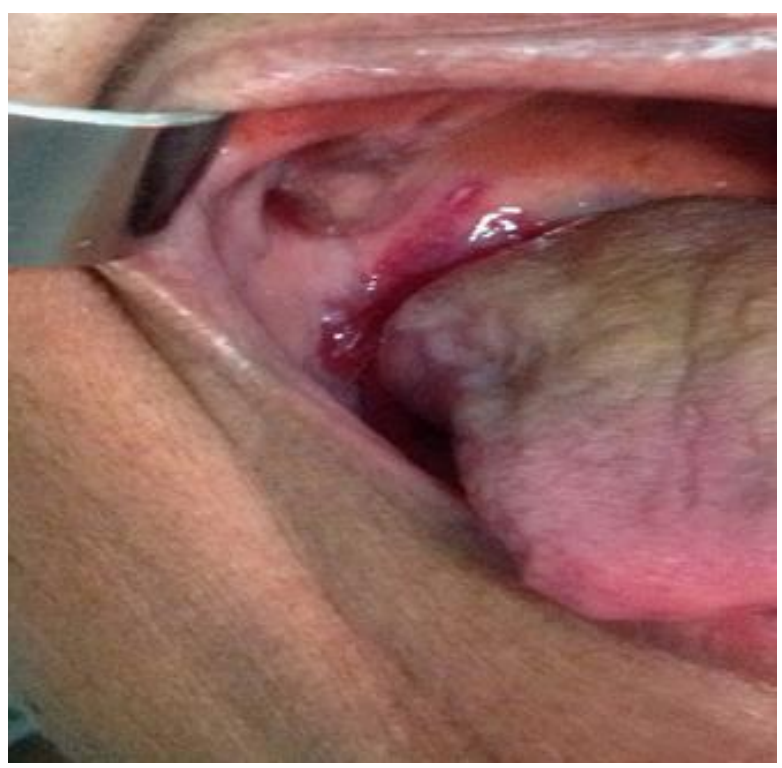

Figura 2: Lesão avermelhada na região posterior e dorso da língua.

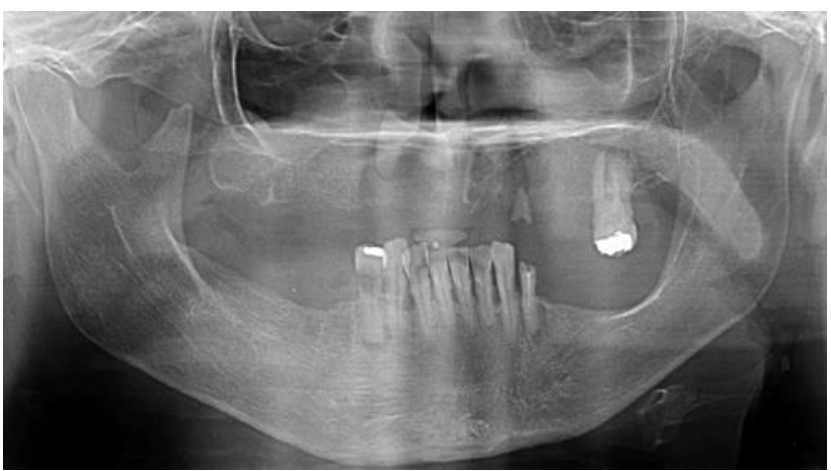

Figura 3: Radiografia Panorâmica

Os cortes histológicos revelam fragmentos de mucosa revestida por epitélio pavimentoso estratificado paraceratinizado exibindo intensa atipia. Evidencia-se alteração da proporção núcleo citoplasma, pleomorfismo e hipercromatismo nuclear, figuras de mitose multinucleações, nuclélos evidentes disceratose, além de estratificação epitelial irregular e cristas em gota.

O tecido conjuntivo subjacente é predominantemente frouxo permeado por focos de intenso infiltrado inflamatório mononuclear. Fibras musculares, células adiposas, parênquima de glândula salivar e fascículos nervosos completam o quadro histológico examinado. Teve com resulto Carcinoma "in situ". Diante do diagnóstico, a paciente foi encaminhada para o tratamento especializado no hospital de referência na região do Cariri-Ce ${ }^{6}$.

\section{REVISÃO DA LITERATURA E DISCUSSÃO}

O câncer bucal (CB) é um dos 10 tipos mais comuns de câncer e representa de 3 a 5\% do total de neoplasias malignas nos países ocidentais, sendo que o carcinoma epidermóide ou carcinoma espinocelular (CEC) é a neoplasia maligna que mais comumente ocorre na boca. A estimativa do Instituto Nacional do Câncer (INCA) para o Brasil em 2018 é de 14700 novos casos de câncer de boca, sendo 11200 homens 
e 3500 mulheres. Em 2013, foram registrados 5401 mortes por esse carcinoma, sendo 4223 homens e 1178 mulheres $^{6}$.

O fumo e a ingestão de álcool são os principais fatores de risco conhecidos com evidências estatísticas significantes. $\mathrm{O}$ indivíduo que fuma um maço de cigarros por dia tem um risco 15 vezes maior de desenvolver câncer de boca do que o indivíduo não fumante. Para os que além de fumar, consomem bebidas alcoólicas destiladas fortes, essa chance aumenta em 25 vezes. Quanto ao cigarro, evidenciou-se um efeito dose-resposta, com riscos crescentes na relação direta de consumo em maçosano. Traumas crônicos causados por má-oclusão dentária ou próteses mal adaptadas também representam um importante fator de risco ${ }^{7}$.

Outros fatores implicados na carcinogênese do câncer de cabeça e perxoço são viroses principalmente no câncer da laringe e da rinofaringe (vírus de Epstein-Barr); exposições ocupacionais nas refinarias de níquel, marcenarias e fábricas de artigos de couro e trabalhadores em minas de asbestos. A exposição à radiação ionizante e solar se mostram extremamente importantes principalmente no câncer de lábio e câncer de pele localizado em região cabeça-pescoço ${ }^{8}$.

A suscetibilidade genética também deve ser considerada um possível fator, isolada ou associada ao tabagismo, podendo se manifestar na herança de síndromes de suscetibilidade ao câncer claramente definidas, defeitos de reparo do DNA, alterações da capacidade de metabolização do carcinógeno ou alterações nas respostas imunológicas do hospedeiro ${ }^{9}$.

Os carcinomas espinocelular da língua apresentam-se como uma lesão exofítica da borda lateral posterior da língua mostrando nódulos superficiais e infiltração nas camadas profundas do órgão atingido. A lesão é indolor e endurecida quando abordada em estádio avançado, além de maior índice de margens comprometidas e, nestas circunstâncias, menor resposta ao tratamento radioterápico adjuvante ${ }^{5,6}$.

O câncer de orofaringe manifesta-se usualmente como uma lesão ulcerada, mal definida, dolorosa, em um dos lados da linha mediana do palato mole. Subsequentemente atinge o palato duro, com possibilidade de invaginação óssea ou, ocasionalmente, cavidade nasal, enquanto as lesões infiltrantes podem estender-se para nasofaringe ${ }^{7}$.

Ulceração e amadurecimento no lábio inferior, acentuada formação de crosta e espessamento, são características pertinentes do câncer de lábio. Quando uma área de ulceração ou endurecimento aparece no lábio primeiramente como uma lesão cancerável chamada queilite actínica, deve-se suspeitar de displasia e início de transformação maligna ${ }^{8}$.
Tumores do trígono retromolar são raros, devido ao pequeno espaço deste local. Frequentemente, as lesões se estendem à amígdala, ao pilar anterior ou ao palato mole. Geralmente os tumores nessa região são diagnosticados em fases mais tardias, sendo necessárias ressecções cirúrgicas que incluam tumor, mandíbula adjacente e palato mole, além de esvaziamento linfonodal cervical, gerando extensa deformidade orofacial ao paciente $\mathrm{e}$ suas morbidades inerentes ${ }^{9}$.

A anamnese e exame minucioso da cavidade oral são de fundamental importância para o diagnóstico do câncer de boca e orofaringe. Caso na anamnese chame atenção fatores de risco, é necessário dar especial atenção a algumas áreas da cavidade oral de alto risco, como assoalho bucal, base da língua, palato mole, úvula, pilares anteriores e posteriores e espaço retromolar. É importante que se faça um diagnóstico precoce das neoplasias de cavidade oral e orofaringe. Assim, lesões que não regridem em 2 ou 3 semanas requerem intensa investigação com biópsia. Deve-se atentar a lesões leucoplásicas e eritroplásicas, como as descritas anteriormente $^{10}$.

O anatomopatológico da biópsia irá ajudar no estadiamento da doença. Pode ser dividido em T1, tumor menor ou igual a $2 \mathrm{~cm}$; T2, com tamanho entre 2 a $4 \mathrm{~cm}$; T3, maiores que $4 \mathrm{~cm}$; T4 quando invadem estruturas adjacentes; e Tx, carcinoma in situ, que é o primeiro estágio em que o câncer não hemapoético pode ser classificado. Nesse estágio, as células cancerosas estão somente na camada da qual elas se desenvolveram e ainda não se espalharam para outras camadas do órgão de origem. A maioria dos cânceres in situ é curável, se for tratada antes que progrida para a fase de câncer invasivo ${ }^{8,9}$.

O tratamento pode ser cirúrgico, radioterápico e/ou quimioterápico. Radioterapia e ou cirurgia isoladas têm igual sucesso no controle de lesões precoces de cavidade oral, sendo o tratamento escolhido de acordo com as condições do paciente. Porém, em casos mais avançados, há a necessidade do tratamento conjunto com cirurgia e radioterapia, sendo necessária mais agressividade no tratamento caso haja possibilidade e necessidade, gerando, portanto, maiores sequelas e morbidades. $\mathrm{O}$ uso de quimioterapia nesses tumores é controverso. Em geral, a taxa de cura para lesões orais, exceto para lesões precoces, tende a não atingir um bom índice ${ }^{10}$.

\section{CONCLUSÃO}

Conclui-se que o exame clínico minucioso da cavidade oral dos pacientes com fatores de risco e/ou que possuam lesões suspeitas é de fundamental importância para profissionais como o Cirurgião Dentista e Médico. Lesões iniciais, como o carcinoma in situ, de tumores de boca e orofaringe podem ser tratadas com maiores taxas de sucesso e 
determinando menores deformidades orofaciais e morbidades ao paciente.

\section{REFERÊNCIAS}

1. Gupta B, Bhattacharyya A, Singh A, Sah K, Gupta V. Basaloid squamous cell carcinoma - A rare and aggressive variant of squamous cell carcinoma: A case report and review of literature. Natl J Maxillofac Surg. 2018;9(1):64-8.

2. Heera R, Ayswarya T, Padmakumar SK, Ismayil P. Basaloid squamous cell carcinoma of oral cavity: Report of two cases. J Oral Maxillofac Pathol. 2016;20(3):545

3. Tomblinson CM, Nagel TH, Hu LS, Zarka MA, Hoxworth JM. Median lingual lymph nodes: prevalence on imaging and potential implications for oral cavity cancer staging. J Comput Assist Tomogr. 2017;41(4):528-34.

4. Varela-Centelles P, López-Cedrun JL, FernándezSanromán J, Seone-Romero JM, Santos de Melo $\mathrm{N}$, Álvarez-Nóvoa $\mathrm{P}$ et al. Key points and time intervals for early diagnosis in symptomatic oral cancer: A systematic review. Int J Oral Maxillofac Surg. 2017;46(1):1-10.

5. Jia J, Jia MQ, Zou HX. Lingual lymph nodes in patients with squamous cell carcinoma of the tongue and the floor of the mouth. Head Neck. 2018;40(11):2383-88.

6. Swiecicki PL, Malloy KM, Worden FP. Advanced oropharyngeal squamous cell carcinoma: Pathogenesis, treatment, and novel therapeutic approaches. World J Clin Oncol. 2016;7(1):15-26.

7. Balica NC, Poenaru M, Doroş CI, Baderca F, Preda MA, Iovan $\mathrm{VC}$ et al.The management of the oropharyngeal anterior wall cancer. Rom J Morphol Embryol. 2018;59(1):113-19.

8. Dahlstrom KR, Bell D, Hanby D, Li G, Wang LE, Wei $Q$ et al. Socioeconomic characteristics of patients with oropharyngeal carcinoma according to tumor HPV status, patient smoking status, and sexual behavior. Oral Oncol. 2015;51(9):832-38.

9. Bonomo P, Merlotti A, Olmetto E, Bianchi A, Desideri I, Bacigalupo A et al. What is the prognostic impact of FDG PET in locally advanced head and neck squamous cellcarcinoma treated with concomitant chemo-radiotherapy? A systematic review and meta-analysis. Eur J Nucl Med Mol Imaging. 2018;45(12):2122-38.

10.Picard A, Arowas L, Piroth L, Heard I, Ferry T, ORL-HIV-HPV studt group. Head and neck squamous cell carcinoma in people living with HIV in France. Med Mal Infect. 2018;48(8):503-8.

\section{CONFLITO DE INTERESSES}

Os autores declaram não haver conflitos de interesse.

\section{AUTOR PARA CORRESPONDENCIA}

\section{Júlio Leite de Araújo Júnior}

juniorleitearaujo@hotmail.com

Submetido em 11/08/2018

Aceito em 04/10/2018 